\title{
Sexual patterning and condom use among a group of HIV vulnerable men in Thika, Kenya
}

\author{
A Ferguson, M Pere, C Morris, E Ngugi, S Moses
}

Sex Transm Infect 2004;80:435-439. doi: 10.1136/sti.2004.010462

See end of article for authors' affiliations

......................

Correspondence to: Alan Ferguson,

Strengthening STD/HIV Control in Kenya Project, PO Box 19676, Nairobi, Kenya; alanf@stdhivkenya.org

Accepted for publication 3 June 2004

\begin{abstract}
Background/aim: A composite sample of 37 peer educators and 215 members of self help groups of male informal sector workers in Thika, Kenya, targeting HIV/AIDS prevention, were interviewed about their sexual behaviour, using a customised template, as part of a broader survey on gender attitudes and peer pressure.

Method: Details on each sexual partner reported by each man over a 12 month recall period included type of partner, months during which sexual relations took place, and condom use.

Results: The men reported 471 sexual partners over the recall period, with a range of 0-16 partners, and an average of just under two partners. $8 \%$ of men had had no sexual partner, half were monogamous, and $3 \%$ had multiple partners with whom they used condoms exclusively, leaving $39 \%$ at varying degrees of risk. Condom use increased significantly with reduced intimacy of partner. $16 \%$ of men reported having at least one liaison with a female sex worker and two thirds of such liaisons were exclusively protected by condom use. Younger, single men had significantly more partners, but were more likely to use condoms. Duration of membership in self help groups was strongly associated with exclusive use of condoms with casual or FSW partners. Recorded attitudes corresponded somewhat with practice, but the data showed large gaps between the two, and low levels of gender sensitivity.

Conclusion: There is some evidence that group membership has resulted in increased condom use and partner reduction, but there are doubts as to the extent to which the "ABC" strategy can be successful in stemming the HIV/AIDS epidemic. It may be necessary for interventions to target contextual issues, particularly gender relations, if the approach is to be more successful.
\end{abstract}

ublic health campaigns in countries having generalised HIV epidemics focus on the "ABC" formulation of HIV prevention: abstaining from sex, faithfulness to one uninfected partner, and condom use. Commitment to the "ABC" strategy has been affirmed among key development partners. The USAID website, "Global Health" notes (January 2003) that "USAID believes that where there are generalised epidemics, a fully balanced approach to the ABCs-abstinence, being faithful, and condoms-should be implemented. USAID is encouraging its missions to support the development of HIV/AIDS communication strategies that involve input from a broad based constituency of local stakeholders." It has been argued that such strategies have been effective in successfully responding to the HIV/AIDS epidemic in neighbouring Uganda. ${ }^{12}$

While widely broadcast and publicised as a strategy, relatively few studies have reported behavioural responses to each of the "ABC" strategies simultaneously. Concentration has been on condom use in specific groups, ${ }^{3}$ an approach followed particularly by social marketing agencies. Recent reports from the Demographic and Health Survey (DHS) series in some African countries provide information that make it possible to calculate proportions of men and women abstaining, having sex with non-regular partners, and using condoms at last sexual act. A meeting convened by USAID in 2002 brought together a group of reproductive health experts to consider the behaviour change represented by the "ABC" approach. ${ }^{4}$ However, although many data were presented, there was no example of changes in all " $\mathrm{ABC}$ " strategies within a single study population.

There is general agreement that, in many sub-Saharan African countries, men form a "bridge population" conveying HIV through sexual transmission from infected non-regular partners, such as female sex workers (FSWs), to the general population..$^{5}$ The strengthening STD/HIV control project has, since 1991, implemented community and clinical interventions among selected highly vulnerable groups in Kenya to reduce transmission of STDs and HIV/AIDS. The community component has involved mobilisation of FSWs into peer led groups, with peer education and support as a strategy for STD/HIV prevention. Promotion of quality STD services based on syndromic management is the main clinical component. Project monitoring has demonstrated the efficacy of this twin approach. ${ }^{78}$

While most of these interventions have targeted FSWs, a variation in the operational model has attempted to access clients of FSWs as well. Responding to increasing HIV rates in Thika district, some $50 \mathrm{~km}$ north of Nairobi, the project began, in 1997, to design a multidimensional clinical and community initiative targeting both FSWs and their clients. During mobilisation activities, FSWs indicated that men working in the informal sector in Thika town were prominent among their clients. Consequently, four groups of informal sector workers were mobilised, mainly comprising hawkers, artisans, drivers, and loaders.

Mobilisation and recruitment of the informal sector groups began in 1997, and a programme of peer education and other HIV prevention activities was initiated. With steady net growth since inception, group membership reached a total of 450 members by mid-2002. Project data collected in a 1999 assessment gave a proportion of about half of men having ever having used the services of an FSW, with about 25\% having used such services within 6 months of interview.

A survey of peer pressure and gender attitudes was carried out in October 2002 among the male groups in Thika. In this

Abbreviations: DHS, Demographic and Health Survey; FSWs, female sex workers 
paper, we report results of this cross sectional survey of recent sexual behaviour of the male groups, with a view to characterising sexual patterning, in particular, the adoption of "ABC" strategies. We also examine the effects of group membership on behaviour. Comparisons of some stated attitudes and actual practices are made to shed light on the process of behavioural change.

\section{METHODS}

A questionnaire was administered to all peer leaders in the four groups and just over half of the regular members, randomly selected from membership lists, and stratified by occupational group, giving a total sample of 252 men. The peer leaders, as the intermediaries between project staff and the community, had received more intensive education. All were included to gauge the effects of this training and to ensure sufficient numbers for comparative purposes.

The main questionnaire sought background information and recorded attitudes to men's and women's sexuality and roles. Details of sexual patterning and condom use were elicited using a specially designed template recording details of all sexual partners of each man over the preceding 12 months. These included indication of months during which sex had occurred with specific partners, the type of partner, (spouse, regular partner, casual partner or sex worker) and condom use with each partner classified in four ways: ever use, use at first encounter, use at last encounter and exclusive use. The response "always" was interpreted as "exclusive use," which is thought to be a more descriptive term here than "consistent" use. It is believed that this categorisation provides more useful information than only asking about ever use or use at last sexual encounter, which is more commonly employed. Interviewers also noted the occurrence of "one night stands" with casual partners or FSWs.

Data were entered using Epi-Data and analysed using SPSS, Version 10.0. Standard descriptive and inferential statistics were used as appropriate.

\section{RESULTS}

The main questionnaire was administered to 37 peer leaders and 215 regular members of the four occupational groups. Details on 471 sexual partners, including 202 casual or FSW partners, were elicited, giving a second, partner based, data set from which aggregate measures could be appended to the main respondent based data. Classification of men by the "ABC" categories of HIV prevention was possible using these data, and exploration of the correlates of particular patterning was made using the background data from the main questionnaire.

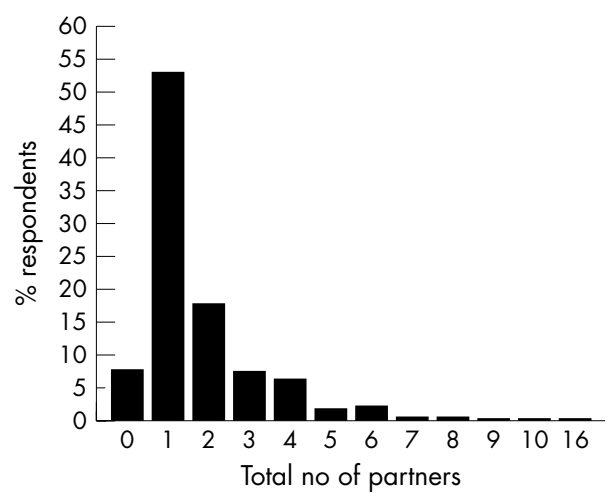

Figure 1 Frequencies of all sexual partners over 12 months.

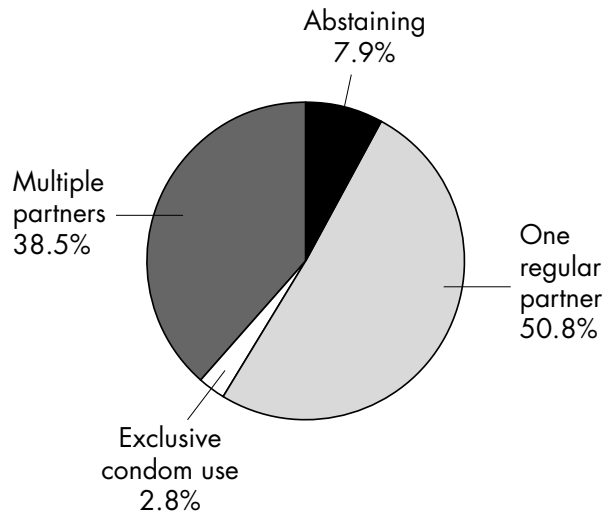

Figure 2 Adherence to " $A B C$ " HIV prevention strategies.

Figure 1 shows the frequencies of sexual partners per man over the 12 month recall period.

Eight per cent of the men had reported abstaining from sex during the year before interview, 53\% had had only one partner, and $39 \%$ had had two or more partners. The range was $0-16$ partners, with a mean of 1.9 , and a median and mode of one partner.

Figure 2 classifies the men by their adherence to the "ABC" strategy of HIV prevention. The exclusive condom use category refers to exclusive use of condoms with all additional partners beyond a wife or regular partners.

Of the 252 respondents, $7.9 \%$ reported having abstained from sex during the past year, $50.8 \%$ reported only one regular partner and just under $3 \%$ reported practising exclusive condom use with multiple partners, leaving 38.5\% who reported multiple partners with whom non-exclusive condom use was practised. The latter group covered a wide variety of risk situations, including men with only one additional partner and those with over 10 partners. This group also included the two polygamists who reported two wives and no additional sexual partners. Some $7 \%$ of men reported having two sexual partners, comprising a wife and a regular partner.

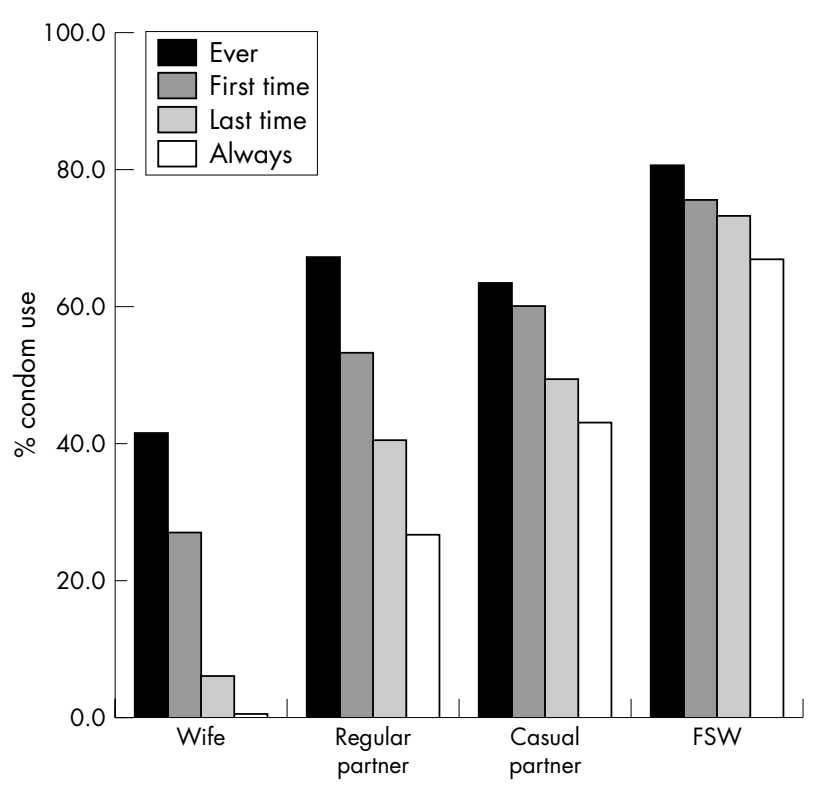

Figure 3 Condom use by type of partner. 


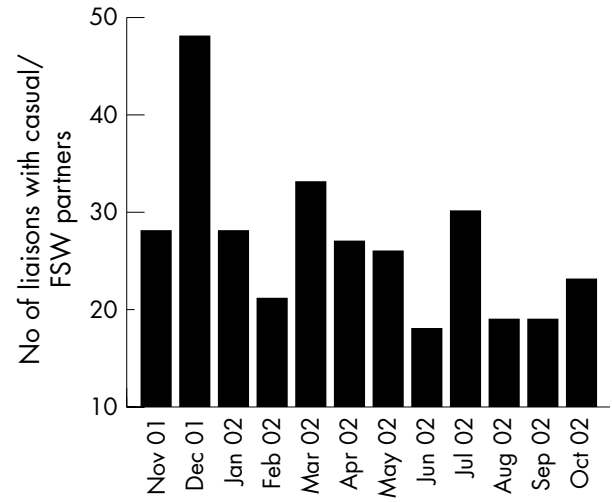

Figure 4 Seasonality of casual sex: number of casual and FSW liaisons reported by month.

The mean age of the 20 men who abstained from sex was 28 years, compared with 29 years for the whole group. One third of the married men recorded at least one extramarital partner and $44 \%$ of unmarried men had had at least one casual or FSW partner over the12 month period.

Figure 3 shows the proportions of men using condoms ever, during the first sexual act with the particular partner, at the last sexual act, and exclusively, by type of partner.

Condom use increases with the decline in intimacy level of the partners and the increase in perceived risk to the men. Thus, for example, condom use with wives at last sexual contact was under $6 \%$, compared to $40 \%$ with regular partners, $49 \%$ with casual partners, and $73 \%$ with sex workers. The other measures of condom use generally follow the same trends, although ever use with casual partners is below the level of ever use with regular partners. Comparisons of all four measures of condom use with partner type are all strongly significant statistically (all $\mathrm{p}$ values $<0.001$ on a $\chi^{2}$ test). Where exclusive condom use is highest, the four measures of condom use are, by definition, closest together. While condom use increases with declining intimacy of the relationship, it does not reach $100 \%$, even with FSW partners.

Over the 12 month period, 40 of the 252 respondents $(15.9 \%)$ reported at least one FSW as a sex partner. The 15 married men involved recorded 23 FSW partners and the 25 single men recorded 55 FSW partners.

The one-off sexual encounter or "one night stand" is likely to carry maximum risk of infection. Of all liaisons recorded, $18.7 \%$ were "one night stands." The responses showed that $41 \%$ of liaisons with casual partners and $49 \%$ of those with
FSWs were one night stands. Condoms were used in 28 $(51.9 \%)$ of one night stands with casual partners and 29 (76.3\%) of one night stands with FSWs.

The data allow tabulation of sex partners by month of recall. This is shown in figure 4 for casual and FSW liaisons reported.

Casual liaisons show a strong peak in December, with minor peaks in March and July. The number of casual liaisons in December is over twice that of five of the other months.

Table 1 combines the two sets of data, showing the mean numbers of sexual partners per man, the proportion of monogamous men, and the proportions of casual and FSW partners with whom condoms were exclusively used, by some of the background characteristics of the men. The tabulation is for sexually active men only, so the 20 men recording no sexual liaison in the recall period are excluded.

Younger, single men have more partners but are more likely to use condoms exclusively with casual/FSW partners than older, married men. More years of schooling does not predict less risky behaviour. Indeed, the men with 8 years of education or under were significantly more likely to use condoms exclusively with casual partners than men with over 8 years of schooling. Duration of membership in the self help groups was not significantly related to the mean numbers of reported sex partners, nor to the probability of having a monogamous relationship, although there was a trend in that direction for the latter. Duration of membership in the groups, however, was quite strongly related to exclusive use of condoms with casual or FSW partners $\left(\chi^{2}=9.35, \mathrm{p}=0.009\right)$.

The survey investigated some aspects of gender sensitivity and knowledge, and it is of interest to compare some of these findings with the actual behaviour recorded. In general, the men showed low levels of gender sensitivity. Their attitudes to women were fairly negative. For example, 69\% agreed with the statement that "In Kenya, women are mainly responsible for the spread of HIV/AIDS," and the same proportion agreed that "Men who engage in risky sexual behaviour are often enticed by women."

One direct comparison between attitude and practice is afforded by the statement: "It's OK for a man to have more than one girlfriend at the same time." Almost $84 \%$ of men disagreed with this statement. By tabulating the numbers of partners recorded over the 1 year period against these responses, the degree of consistency between attitude and practice can be judged. Table 2 shows the results.

There is an association between attitude and practice, with increasing numbers of partners correlating with lower proportions of men disagreeing with the statement $\left(\chi^{2}=17.4, p=0.004\right)$. Again, however, the more interesting

Table 1 Sexual patterning indicators by background variables for all sexually active men

\begin{tabular}{lrlll}
\hline Variable & No & $\begin{array}{l}\text { Mean No } \\
\text { of partners }\end{array}$ & $\begin{array}{l}\text { \% reporting one } \\
\text { regular partner }\end{array}$ & $\begin{array}{l}\text { \% exclusive condom } \\
\text { use with casual/FSW } \\
\text { partners (n=202) }\end{array}$ \\
\hline Age $<30$ years & 144 & $2.27^{*}$ & $47.9^{* *}$ & $47.8^{*}$ \\
Age 30+ & 88 & 1.64 & 67.0 & 65.3 \\
Single & 86 & $2.73^{* * *}$ & $37.2^{* * *}$ & $60.7^{*}$ \\
Married/cohabiting & 146 & 1.62 & 65.8 & 45.4 \\
Education 8 years or less & 129 & 2.14 & 55.0 & $54.7^{*}$ \\
Education >8 years & 103 & 1.89 & 55.3 & 47.6 \\
Duration of membership & & & & $34.4^{* *}$ \\
$\quad$ Under 4 months & 58 & 2.02 & 44.8 & 52.9 \\
$\quad \begin{array}{l}\text { 4-12 months } \\
>12 \text { months }\end{array}$ & 52 & 2.12 & 51.9 & 61.4 \\
Test & 109 & 2.02 & 60.6 & $\chi^{2}$ \\
\hline Significance levels: ${ }^{*} 95 \% * * 99 \% * * * 99.9 \%$. & & & \\
\hline
\end{tabular}


Table 2 Multiple partners: attitude and practice

\begin{tabular}{lll}
\hline & \multicolumn{2}{l}{$\begin{array}{l}\text { "It's OK for a man to have more than one } \\
\text { girlfriend at the same time" }\end{array}$} \\
\cline { 2 - 3 } No of partners & \% Agreeing & \% Disagreeing \\
\hline 0 & 10.0 & 90.0 \\
1 & 8.2 & 91.8 \\
2 & 24.4 & 75.6 \\
3 & 26.3 & 73.7 \\
4 & 31.3 & 68.8 \\
5 and over & 33.3 & 66.7 \\
Total & 15.9 & 84.1 \\
\hline
\end{tabular}

finding is the disconnection between attitudes and practice in the majority of men.

Consistency of attitude and practice is displayed only by the abstainers and those reporting only one sexual partner, where upwards of $90 \%$ disagreed that multiple partners were acceptable. While the proportions agreeing that multiple partners were acceptable increases with the actual number of partners reported, the vast majority of those having more than one partner disagreed that it was OK to have more than one girlfriend at the same time. Thus, two thirds of the men reporting five partners or more had earlier disagreed that this behaviour was acceptable.

\section{DISCUSSION}

Adherence to any "ABC" strategy among this vulnerable group of male workers totals only about $61 \%$. There is a wide variation in risk among the remaining $39 \%$, with only a very small proportion of men reporting large numbers of multiple partners. Condom use patterns add to the solid body of evidence that use increases with lower levels of partner intimacy and higher perceived risks of infection. Even at the most risky end of the sexual partner spectrum, however, exclusive condom use was practised by only two thirds of the men. Despite much effort in peer education sessions, only $7 \%$ of men with multiple partners reported using condoms exclusively with all such partners, and one-off sexual encounters show condom use of well below 100\%.

In Zimbabwe, consistency of condom use was found to be somewhat higher among urban males, where $2.4 \%$ of men reported consistent condom use with a spouse, $39 \%$ with a regular partner, $82 \%$ with a casual partner, and $90 \%$ with an FSW. ${ }^{9}$ Comparison with data from South Africa ${ }^{10}$ suggests that the Thika men have much less risky sexual behaviour

\section{Key messages}

- A peer education approach to prevention of HIV transmission among vulnerable men in Kenya has achieved approximately $60 \%$ success in adherence to at least one of the " $A B C$ " prevention strategies

- Condom use is negatively associated with level of partner intimacy

- Very high risk behaviour is exhibited by only a small minority of men

- Expressed attitudes about male female relationships do not match exhibited behaviour in many cases

- The " $A B C$ " strategy is not likely to be very successful where socio-cultural constraints restricting female empowerment exist patterns than men frequenting "hot spots" in townships and town centres in Eastern Cape Province.

Abstinence is commonly promoted through its association with delayed onset of sexual activities among young people. It is perhaps surprising, in the present context, to see as many as $8 \%$ of men whose average age is in the high 20 s having had no sexual partner in a 12 month period. This is most likely to reflect secondary, rather than primary, abstinence.

Evidence from table 1 suggests that duration of membership in the anti-AIDS self help groups is associated with more consistent use of condoms with casual partners. The same table does not suggest significant reduction in partners with increasing duration of membership. There is some evidence that higher proportions of men report only one regular partner with increasing duration of membership, but this relationship is affected by age and marital status and is, in any case, not statistically significant.

The results from comparing attitudes and practice conform to behavioural change processes suggesting that time lags between stated attitudes and practices are common. In the USAID meeting report, doubt was cast by a presenter on the trustworthiness of responses to questions about behaviour change. The answer may be to measure practice wherever possible and to triangulate this with attitudes.

While the study may have indicated some success in reduction of risk in a particular group, the results cast doubt on the extent to which the "ABC" strategies can successfully seal off HIV transmission. In the absence of short term cultural change, significant partner reduction may not be easily attainable and, as long as condom use remains well below $100 \%$ with casual partners, and at very low levels with more intimate partners, transmission of HIV will likely continue. None the less, the study has shown that particularly risky behaviour is vested in a relatively small number of men.

Peer education has contributed to risk reduction, although the survey highlighted some limitations in this approach, via the attitudes displayed, of concentrating on accepted public health interventions while ignoring contextual issues such as gender relations. The problems of following " $\mathrm{ABC}$ " prescriptions are greatly magnified for women. Debate on the relative importance of the " $\mathrm{A}$, , " $\mathrm{B}$, ," or " $\mathrm{C}^{\prime 11}$ pales into insignificance when the contextual position of most African women is considered. As is noted in Kenya's document on mainstreaming gender into its national HIV/AIDS strategic plan, "Even where women have a degree of economic autonomy, social and cultural expectations may make it extremely difficult for them to set the terms of sexual encounters."12 Without a revolution in the power relations between men and women, abstinence and condom negotiation with intimate partners remain tough or impossible options, and being faithful to one partner does not confer immunity to HIV if that partner is exhibiting risky behaviour. Thus, the positive results for male risk reduction reported here should be seen in the whole context of gender relations.

In this respect, the project has started to incorporate gender training into peer education for both male and female community groups in Thika and elsewhere, and it is our recommendation that community based public health programmes aimed at combating HIV/AIDS need to make room for contextual issues like gender to create a more holistic approach to the problem.

Feeding back the results of the Thika survey to the peer leaders meetings, two resolutions were suggested: firstly, that "we should be a $100 \%$ condom group, especially at Christmas" and, secondly, that "our peer education should include male-female relationships." The second of these resolutions may turn out, in the longer term, to be the more important. 


\section{ACKNOWLEDGEMENTS}

This work was supported by a grant from the Canadian International Development Agency (CIDA), Project "Strengthening STD/HIV Control in Kenya, Phase III," No 7019662. SM is the recipient of an Investigator award, Canadian Institutes of Health Research.

\section{Authors' affiliations}

A Ferguson, Department of Medical Microbiology, University of Manitoba and Strengthening STD/HIV Control in Kenya Project, PO Box 19676, Nairobi, Kenya

M Pere, Strengthening STD/HIV Control in Kenya Project, PO Box 19676, Nairobi, Kenya

C Morris, Department of Medical Microbiology, University of Manitoba and Strengthening STD/HIV Control in Kenya Project, PO Box 19676, Nairobi, Kenya

E Ngugi, Department of Community Health, University of Nairobi and Strengthening STD/HIV Control in Kenya Project, PO Box 19676,

Nairobi, Kenya

S Moses, Department of Medical Microbiology, University of Manitoba, 543-730 William Avenue, Winnipeg, Manitoba, Canada R3E OW3

\section{REFERENCES}

1 Asiimwe-Okiror G, Opio AA, Musinguzi J, et al. Change in sexual behaviour and decline in HIV infection among young pregnant women in urban Uganda. AIDS 11 1997:1757-63.
2 Okware S, Opio A, Musinguzi J, et al. Fighting HIV/AIDS: is success possible? Bull World Health Organ 2001;79:1113-20.

3 Meekers $D$, Klein M. Determinants of condom use among young people in urban Cameroon. Studies in Family Planning 2002;33:335-46.

4 USAID. The "ABCs" of HIV prevention. Report of a technical meeting on behavior change approaches to primary prevention of HIV/AIDS. Washington DC: USAID, 2002.

5 Moses S, Muia E, Bradley JE. Sexual behaviour in Kenya: implications for sexually transmitted disease transmission and control. Soc Sci Med 1994;39:1649-56.

6 Buvé A, Bishikwabo-Nsarhaza K, Mutangadura G. The spread and effect of HIV-1 infection in sub-Saharan Africa. Lancet 2002;359: 2011-16.

7 Ngugi EN, Wilson D, Sebstad J, et al. Focused peer-mediated educational programs among female sex workers to reduce sexually transmitted disease and HIV transmission in Kenya and Zimbabwe. J Infect Dis 1996;174(Suppl 2):S240-7.

8 Moses S, Ngugi EN, Costigan A, et al. Response of a sexually transmitted infection epidemic to a treatment and prevention program in Nairobi, Kenya. Sex Transm Infect 2002;78(Suppl 1):114-20.

9 Meekers D. Patterns of condom use in urban males in Zimbabwe: evidence from 4,600 sexual contacts. PSI Research Division Working Paper No 37 2000.

10 Weir S, Pailman C, Mahalela X, et al. From people to places: focusing AIDS prevention efforts where it matters most. AIDS 2003;17:895-903.

11 Singh S, Darroch JE, Nankole A. The role of behavior change in the decline of HIV prevalence in Uganda. Memo to interested parties. New York: The Alan Guttmacher Institute, 2002

12 National AIDS Control Council, Kenya. Mainstreaming gender into the Kenya National HIV/AIDS Strategic Plan 2000-2005. Nairobi, Kenya, 2002 